Miller RH. Am J Dis Child 1963;106:197).

\title{
CEREBELLITIS AND ACUTE HYDROCEPHALUS
}

A case of obstructive hydrocephalus and bilateral cerebellitis with swelling in a 14-year-old boy is reported from the Department of Child Health, St George's Hospital, and the Departments of Neurosurgery and Neuroradiology, Atkinson Morley's Hospital, London, UK. The child presented with a 2-month history of recurrent headache and a 2-week history of occipital headache, nausea and vomiting, without signs of acute infection or immunization. Fundi showed bilateral papilledema. Apart from mild dysdiadochokinesia, the neurologic exam was otherwise normal. MRI showed obstructive hydrocephalus and marked bilateral cerebellar swelling with increased signal on T-2 weighted imaging, compatible with acute inflammation. Clinical and MRI signs resolved in 4 weeks following treatment with corticosteroids, and the neurologic exam was normal at 12 month follow-up. (Aylett SE, O'Neill KS, De Sousa C, Britton J. Cerebellitis presenting as acute hydrocephalus. Child's Nerv Syst March 1998;14:139-141). (Respond: Dr SE Aylett, The Wolfson Centre, Mecklenburgh Square, London WC1N 2AP, UK).

COMMENT. The clinical and MRI findings and recovery following steroids were considered consistent with a parainflammatory cerebellitis, although viral studies were negative. Prompt diagnosis and therapy are important because of the danger of tonsillar herniation.

\section{ATTENTION DEFICIT DISORDERS}

\section{CEREBELLAR VERMIS ANOMALY IN ADHD}

Cerebellar and vermal volumes were measured by quantitative MRI studies in 46 right-handed boys with attention deficit hyperactivity disorder (ADHD) and 47 matched healthy controls, and results were analyzed at the Child Psychiatry Branch, National Institute of Mental Health, Bethesda, MD. Both area and volumetric analyses showed a smaller cerebellar vermis in boys with ADHD, and the posterior inferior lobules VIII to X were particularly involved. Total cerebral volume was $6 \%$ smaller in the ADHD group, also. WISC-R vocabulary and block design scores were significantly lower in ADHD compared to control children. The findings were not related to prenatal alcohol exposure nor to methylphenidate treatment. A cerebello-thalamo-prefrontal circuit dysfunction is postulated in ADHD. (Berquin PC, Giedd JN, Jacobsen LK et al. Cerebellum in attention-deficit hyperactivity disorder. A morphometric MRI study. Neurology April 1998;50:10871093). (Reprints: Dr FX Castellanos, 10 Center Drive, Room 3N202, Bethesda, MD 20892).

COMMENT. The cerebellar vermis is smaller in right-handed boys with $\mathrm{ADHD}$, and the reduction in volume involves particularly the posterior inferior lobules VIII to $\mathrm{X}$. The smaller cerebral volumes might explain the significantly lower IQ scores in ADHD children compared to controls. Previous studies by Dr Castellanos at the NIH showed that ADHD was associated with loss of normal asymmetry in the caudate nucleus, smaller right anterior frontal area, and smaller cerebellum, and IQ scores correlated with total cerebral volume. Researchers at the Masssachusetts General Hospital, Boston, have reported a smaller splenium of the corpus callosum in ADHD children, and the Johns Hopkins group of investigators found a smaller globus pallidus volume (see Progress in Pediatric Neurology III, 1997;p 212). These studies add to the growing volume of data supporting a structural brain pathology as the basis for ADHD (Millichap JG. 
TLAC/ADD syndrome. Neurology May 1997;48:1435-1439).

A failure to inhibit or delay response, a central executive function, is a major problem in ADHD. These MRI studies suggest that the cerebellum is involved in the frontal-striatal dysfunction postulated in ADHD. Cognitive dysfunction, visuospatial deficits, and mutism are reported in association with cerebellar lesions.

\section{METHYLPHENIDATE EFFECTS ON EEG AND ADHD}

The effects of methylphenidate (MPH) on the EEG during baseline and cognitive tasks were evaluated using spectral analysis in 23 boys, aged 9 to 11 , with ADHD, and results were analyzed at the Departments of Psychology, State University of New York, Cortland, NY, and University of Tennessee, Knoxville, TN, and the Kennedy Krieger Institute, Baltimore, MD. Behavioral and performance measures improved with MPH, global effects on the cortical EEG were not observed, but regional changes in the EEG were induced by MPH under taskspecific conditions. The findings support the hypothesis that MPH affects the brainstem and subcortical areas but not cortical function. The value of the EEG as a measure of MPH effectiveness is not supported by these studies. (Swartwood MO, Swartwood JN, Lubar JF et al. Methylphenidate effects on EEG, behavior, and performance in boys with ADHD. Pediatr Neurol April 1998;18:244-250). (Respond: Dr Swartwood, Department of Psychology, State University of New York, Cortland, PO Box 2000, Cortland, NY 13045).

COMMENT. Earlier EEG studies in ADHD subjects, reviewed by the authors, have shown a failure to attenuate alpha activity during mental tasks, decreased beta activity, and increased delta and theta activity. Treatment with MPH may have a normalizing effect, with trends in reduced alpha, increased beta, and reduced overall amplitude. The present study shows EEG changes during MPH treatment, mainly regional and during reading, coding, and visual-motor tasks. Increased beta 1 and beta 2 activity in central and parietal regions of the left hemisphere during visual-motor tasks point toward a normalizing effect of MPH on the EEG. The EEG as a measure of MPH effects in ADHD requires further study.

\section{ASSESSMENT OF ADDERALL IN ADHD}

The time course effects of four doses of $\operatorname{Adderall}^{\circledR}(5,10,15$, and $20 \mathrm{mg})$ were compared to placebo and a single dose of methylphenidate in a randomized, double-blind, crossover study of 30 children with attention deficit hyperactivity disorder (ADHD) treated at the Child Development Center, University of California, Irvine. A capsule was given $\mathrm{AM}$ and time-response and dose-response were assessed every 1.5 hours through the day, using subjective teacher ratings of attention, and objective math test scores at each classroom session. Significant effects were observed by 1.5 hours with doses of Adderal above $5 \mathrm{mg}$, and time of peak effects and duration of action increased with the dose. From 5 to $20 \mathrm{mg}$, the duration of action ranged from 3.5 hrs to 6.4 hrs. Side effects showing a doserelated increase after Adderal adminstration included picking at skin or fingers, appetite loss, and trouble sleeping. Dosage was adjusted in 5 subjects, and 2 elected to withdraw from the trial, one with anorexia ( $20 \mathrm{mg}$ dose) and one with anorexia, "tearful, sad, depressed" and "dull, tired, listless" complaints (10 mg dose). Adderal is recommended in treatment of ADHD. (Swanson JM, Wigal S, Greenhill LL, Cantwell DP et al. Analog classroom assessment of Adderal ${ }^{\circledR}$ in children with ADHD. I Am Acad Child Adolesc Psychiatry May 1998;37:519-526). (Reprints: Dr Swanson, Child Development Center, 19722 MacArthur Blvd, Irvine, CA 92612). 